Do Espírito do Lugar - Música, Estética, Silêncio, Espaço, Luz

I e II Residências Cistercienses de São Bento de Cástris (2013, 2014)

\title{
O ofício de Matinas para Festa de São Bernardo
} O testemunho do manuscrito P-AR Ms 25

\section{Luís Carlos Fortuna Henriques}

Publisher: Publicações do Cidehus

Place of publication: Évora

Year of publication: 2016

Published on OpenEdition Books: 13

septembre 2016

Serie: Biblioteca - Estudos \& Colóquios

\section{Sobooks}

http://books.openedition.org

\section{Electronic reference}

HENRIQUES, Luís Carlos Fortuna. O ofício de Matinas para Festa de São Bernardo: O testemunho do manuscrito P-AR Ms 25 In: Do Espírito do Lugar - Música, Estética, Silêncio, Espaço, Luz: I e Il Residências Cistercienses de São Bento de Cástris (2013, 2014) [online]. Évora: Publicações do Cidehus, 2016 (generated 27 October 2016). Available on the Internet: <http://books.openedition.org/cidehus/2154> ISBN: 9782821875029 . DOI: 10.4000/books.cidehus.2154

The text is a facsimile of the print edition. 


\title{
O ofício de Matinas para Festa de São Bernardo: O testemunho do manuscrito P-AR Ms 25
}

\section{Luís Carlos Fortuna Henriques}

\begin{abstract}
The monastery of S. Pedro and S. Paulo of Arouca established itself in the beginning of the 13th century as one of the most important female houses of the Cistercian Order in Portugal. A series of priceless sources of plainchant that allow us to glimpse the richness of the musical liturgy originating from this monastery survived. It is intended, through the comparative study of the office of Matins for the feast of St. Bernard, to set a course of musical tradition associated with the worship of this Saint, especially through Manuscript 25 of the Museum of Sacred Art of Arouca, an antiphonary where this feast is musically represented.
\end{abstract}

Keywords: Cister, antiphonary, Arouca, St Bernard, matins

\section{Resumo}

O mosteiro de S. Pedro e S. Paulo de Arouca constituiu-se no início do século XIII como uma das mais importantes casas femininas da Ordem de Cister em Portugal. Deste mosteiro sobrevivem uma série de fontes de cantochão de inestimável valor e que permitem vislumbrar a riqueza da sua liturgia musical. Pretende-se, através do estudo comparativo do ofício de Matinas para a festa de S. Bernardo, traçar um percurso da tradição musical associada ao culto deste Santo, sobretudo através do Manuscrito 25 do Museu de Arte Sacra de Arouca, um antifonário onde se encontra representada musicalmente a festa de S. Bernardo.

Palavras-chave: Cister, antifonário, Arouca, S. Bernardo, matinas

O mosteiro de São Pedro e São Paulo de Arouca integra o grupo de mosteiros cistercienses femininos que surgiram em Portugal no primeiro quartel do século XIII, todos por iniciativa das três filhas de D. Sancho I. Arouca tornou-se mosteiro cisterciense durante a década de 1220 , um período em que foi iniciada uma política centralizadora 
pelo Capítulo Geral de Cister, que se reflectiu nas comunidades femininas, sobretudo através da admissão de novas incorporações na Ordem ${ }^{1}$.

Apesar de não sobreviverem quaisquer documentos referindo a data da sua fundação, crêse que o mosteiro de Arouca tenha existência anterior a 925. Numa carta datada de 1091, relativa a uma disputa quanto à posse da igreja de Moldes, os monges de S. Pedro reclamavam metade dessa igreja argumentando que esta lhes havia sido dada pelo abade Gondulfo em 925, o que pressupõe uma actividade anterior a esse ano. O mosteiro terá sido fundado por Loderigo e Vandilo, resultando de um litígio com o Bispo de Lamego sobre algumas propriedades. A solução deste litígio passou pela cedência das ditas propriedades com a condição de nelas ser fundado um mosteiro. No século X, os bens do mosteiro vêm um aumento considerável como resultado de amplas doações feitas por Ansur Godesteis e sua mulher D. Eileuva entre 943 e 951. Nas últimas décadas do século XI e primeiras do século XII, D. Toda Viegas foi uma figura importante na história do mosteiro de Arouca, fazendo amplas doações a esta casa. O filho de D. Toda, Mónio Rodrigues, partidário de D. Afonso Henriques, obteve favor régio, valendo-lhe assim as cartas de couto de 1132 e 1143 em favor de S. Pedro de Arouca ${ }^{2}$.

Este mosteiro foi uma das primeiras casas femininas da Ordem de Cister que surgiu em Portugal, no primeiro quartel do século XIII por iniciativa das filhas de Teresa, Sancha e Mafalda, filhas de D. Sancho I ${ }^{3}$. No caso do mosteiro de Arouca, este foi deixado em testamento, junto com o mosteiro de Bouças, a D. Mafalda pelo seu pai, o Rei D. Sancho I, em 1210. No período de permanência no mosteiro de D. Mafalda, a partir de 1217, esta casa sofreu importantes transformações. A mais significativa ocorreu com a alteração da Regra, com a substituição do hábito negro beneditino pelo hábito branco cisterciense. Esta alteração foi aprovada pelo Bispo de Lamego, D. Paio, e pelo Cabido em 1224, tendo sido confirmada pelo Papa Honório III a 5 de Junho de 1226. Desta forma, o mosteiro ficava livre do direito diocesano assim como do pagamento ao Bispo de Lamego do censo anual de seis áureos. A permanência de D. Mafalda no mosteiro constituiu também um forte motivo para o acolhimento de novas professas provenientes de famílias da alta nobreza, atraindo o seu prestígio uma série de legados que contribuíram para a

\footnotetext{
${ }^{1}$ RÊPAS, Luís Miguel, «As Abadessas cistercienses na Idade Média: Identificação, caracterização, e estudo de trajectórias individuais ou familiares», Lusitania Sacra, 2. ${ }^{\text {a }}$ série, 17, 2005, pp. 64-65.

${ }^{2}$ RÊPAS, Luís Miguel, «O Mosteiro de Arouca: Os documentos escritos como fonte de conhecimento (1286-1299)», Hvmanitas, L, 1998, p. 539-540.

${ }^{3}$ RÊPAS, «As Abadessas cistercienses na Idade Média: Identificação, caracterização, e estudo de trajectórias individuais ou familiares», p. 64.
} 
elevação não só espiritual como também material do mosteiro, transformando esta casa numa das comunidades mais elitistas do reino ${ }^{4}$.

É neste contexto de crescimento religioso e social que se assume ter sido adquirido o antifonário objecto do presente estudo. O estudo incide sobre o ofício de Matinas para festa de S. Bernardo, uma figura central na história da Ordem de Cister, cuja festa encontra-se representada nas fontes musicais do século XIII pertencentes ao mosteiro de Arouca, com especial destaque para o antifonário P-AR Ms 25. Antes de entrar no Ofício propriamente dito, é necessário ter presente que este Santo teve uma influência marcante na Ordem, não só em termos teológicos, mas também a um nível musical, este último de central importância histórico-contextual para o presente estudo.

Figura central na Ordem de Cister, S. Bernardo de Clairvaux é ao mesmo tempo um dos nomes mais importantes da história da Igreja medieval. Bernardo terá descoberto a vida monástica por volta do ano de 1110, entrando na Abadia de Cîteaux com os seus irmãos e companheiros muito possivelmente em 1112 o que, segundo os cronistas da Ordem, terá levado o Abade de Cîteau a fundar pouco depois uma nova Abadia em La Ferté, a primeira fundação da Abadia de Cîteaux. A decisão de se tornar monge, segundo os cronistas, tornou-se evidente numa igreja enquanto viajava com o fim de se juntar aos irmãos no cerco ao castelo de Grancey. Este momento de conversão é um dos pontos de grande importância na hagiografia de Bernardo. Apesar dos irmãos terem tentado mantêlo longe do mosteiro, a presença da memória da mãe, uma influência forte em Bernardo, leva-o a juntar-se a uma instituição monástica, abandonando os estudos literários como clérigo secular ${ }^{5}$.

Bernardo foi o primeiro abade de Clairvaux. O local para a implantação desta nova abadia é relatado pelos cronistas como o resultado de um sonho que Bernardo teve em que uma multidão vivia nesse vale, um sinal de prosperidade futura. $\mathrm{O}$ desempenho de Bernardo enquanto abade de Clairvaux foi bastante dinâmico. A certa altura, o cronista Guillaume de Saint-Thierry refere a dificuldade de Bernardo em pregar de forma compreensível para os outros monges. A relação com estes em Clairvaux foi bastante complexa, em virtude desta falta de comunicação e compreensão. Quando percebeu que não estaria a ser compreendido pelos monges, a tendência de Bernardo em isolar-se tornou-se cada vez mais evidente sendo apenas contrariada por uma visão que o encorajou a manifestar-se. Esta relação pessoal não o limitou no exercício das funções de Abade, mantendo a disciplina dentro do mosteiro recentemente fundado e incentivando vários monges a

\footnotetext{
${ }^{4}$ RÊPAS, «O Mosteiro de Arouca: Os documentos escritos como fonte de conhecimento (1286-1299)», p. 542.

${ }^{5}$ MCGUIRE, Brian, «Bernard's Life and Works: A Review» in A Companion to Bernard of Clairvaux, Brill, Leiden, 2011, p. 26-27.
} 
fundarem a primeira casa dependente deste mosteiro, o que se veio a materializar com a fundação a 18 de Outubro de 1118 de Trois Fontaines ${ }^{6}$.

Nos primeiros anos enquanto Abade em Clairvaux, escreveu uma série de obras fundamentais para a compreensão da sua personalidade como o Tratado sobre os graus da humildade e da soberba. Durante a década de 1120 começa a dedicar-se a assuntos exteriores a Clairvaux, sendo fundada a terceira casa dependente desta abadia em 1121 em Foigny. Durante este período Bernardo foi atacado por graves problemas de saúde, preocupando o restantes monges do coro, de tal forma que o impedia de comparecer no coro para os ofícios Nesta década começa a ter influência na Igreja, escrevendo entre 1122 e 1225 a Apologia ao abade Guilherme, um ataque directo a Cluny pela sua ostentação arquitectónica e decoração artística, mas possivelmente alguma crítica também a Cîteaux pela rica decoração presente nos manuscritos produzidos por esta casa. A ideia de unidade na Ordem cisterciense está presente nos seus escritos deste período ${ }^{7}$.

O Concílio de Troyes, em 1129, marca o início do envolvimento de Bernardo em assuntos fora da Ordem, nomeadamente o da constituição de uma nova ordem monástica - os Cavaleiros Templários - incitando a uma segunda cruzada na Terra Santa contra os Muçulmanos que, para o próprio, constituía mais um estado de espírito que propriamente um local concreto, uma realidade imaginada e idealizada do que um objectivo militar ${ }^{8}$. É também uma figura central no Cisma de 1130, viajando pela Aquitânia e Itália com o propósito de convencer o clero e seculares de que o verdadeiro Papa era Inocêncio II e não Anacleto II, uma vez que ambos disputavam a cadeira de S. Pedro. Em 1132, Inocêncio II regressou a Itália, chamando Bernardo para se juntar a ele em Pisa, onde o monge actuou politicamente assegurando um tratado de paz entre esta cidade e a rival cidade de Génova. Bernardo revela-se um estratega político nas suas cartas, estabelecendo alianças entre várias cidades italianas, movimentando-se no meio urbano do Norte de Itália de forma a assegurar a confirmação de Inocêncio II como Papa. Durante a década de 1130 acompanha Inocêncio II em várias viagens por Itália. Este período foi também relativamente conturbado no desenrolar da disputa entre Inocêncio e Anacleto, usando Bernardo o seu poder carismático para ganhar adeptos à causa de Inocêncio, como aparece referido por vários cronistas 9 .

A partir de meados da década de 1130 Bernardo regressa ao cargo de abade de Clairvaux intervindo em vários assuntos relativos ao mosteiro. O mau estado dos edifícios que se

\footnotetext{
${ }^{6}$ Ibidem., p. 30 .

${ }^{7}$ Ibidem., p. 34.

${ }^{8}$ Ibidem., p. 38.

${ }^{9}$ Ibidem., p. 42.
} 
tinham tornado demasiado apertados para a dimensão do vale, a igreja que pouco espaço tinha para albergar o largo número de monges, o insuficiente fornecimento de água à abadia revelaram a necessidade de estender esta casa mais para o fundo do vale para que os monges estivessem mais perto do rio ${ }^{10}$.

Os anos de 1139 a 1145 foram um período de controvérsias doutrinais e algumas disputas políticas, confirmando Bernardo de Clairvaux enquanto estratega político e enquanto teólogo, destacando-se o aceso debate com Pierre Abelard. Enquanto na década anterior, Bernardo ocupou-se substancialmente em resolver o Cisma papal, ganhando notoriedade pelas suas acções, na década de 1140 envolve-se em inúmeras causas (ilustradas nas suas cartas), como é o caso do conflicto entre o Rei Luís VII de França e o seu vassalo o Conde Teobaldo de Champagne, que era senhor feudal de Clairvaux. No período de 1146 a 1149 envolve-se na Segunda Cruzada, pregando em vários locais a favor desta nova empresa na Terra Santa, contudo, mantendo-se sempre contra a presença de monges cistercienses na Palestrina ${ }^{11}$. Esta e outras acções concederam-lhe um lugar central entre as figuras da Igreja do século XII. Bernardo morreu a 20 de Agosto de 1153, deixando para a posteridade uma herança espiritual assim como intelectual de grande influência para o pensamento da Cristandade Ocidental. Segundo a crónica do Abade de Cîteau que presidiu ao funeral de Bernardo, a Clairvaux acorreu uma multidão de peregrinos em busca de curas através do contacto ou aproximação do corpo do monge cisterciense ${ }^{12}$.

Foi canonizado cerca de vinte e um anos após a sua morte, a 18 de Janeiro de 1174 pelo Papa Alexandre III, fixando-se a sua festa em 20 de Agosto, sendo introduzido na Litania cisterciense um quarto de século depois, no ano de 1200. A liturgia cisterciense requeria, a quando da introdução de um novo santo na Litania, a sua comemoração com uma festa de nove lições (Matinas solenes). Para além deste requisito, por vezes também implicava a celebração de duas missas, uma característica pouco comum entre os cistercienses ${ }^{13}$. Não foram encontradas referências relativamente à comemoração da festa deste Santo em Arouca. Contudo, tradições populares - nomeadamente gastronómicas - como o "Pão de S. Bernardo" ainda subsistem em torno do mosteiro como testemunhos da importância desta festa na vida do mosteiro e das comunidades circundantes.

${ }^{10}$ Ibidem., p. 43.

${ }^{11}$ Ibidem., 57.

${ }^{12}$ Ibidem., p. 60.

${ }^{13}$ FERREIRA, Manuel Pedro, «Dating a Fragment: A Cistercian Litany and Its Historical Context», in Leandra SCAPATICCI (ed.), Quod ore cantas corde credas': Studi in onore di Giacomo Baroffio Dahnk, Roma, Libreria Editrice Vaticana, 2013, p. 297-298. 
O manuscrito proveniente do mosteiro de S. Pedro e S. Paulo de Arouca, actualmente conservado no Museu de Arte Sacra existente no mosteiro (P-AR Ms $25^{14}$ ), é um antifonário que contém o ciclo do Sanctorale para o ano litúrgico, junto com um segundo volume (Ms 21). Este manuscrito terá sido copiado no final do século XII, ou início do século XIII, muito provavelmente no scriptorium da Abadia de Alcobaça, que fornecia outras casas da $\operatorname{Ordem}^{15}$. O livro foi reencadernado em 1483, pressupondo-se que foram usados no mosteiro, pelo menos, até às sucessivas reformas efectuadas nas casas portuguesas da Ordem durante a década de $1530^{16}$.

O antifonário contém os ofícios para as várias Horas Canónicas (Vésperas, Matinas, Laudes, Terça, Sexta e Nona), como atrás foi mencionado, para o ciclo do Sanctorale, começando na festa de S. Estêvão, seguida pela de S. João Evangelista, até à de S. André. Após esta última festa aparecem os comuns para os Apóstolos e Evangelistas seguidos pelo comum para Um Confessor durante o Tempo Pascal e comum para a Virgem Maria. Há ainda o ofício para a Dedicação da Igreja. O livro fecha com os ofícios para a festa da Concepção da Virgem e S. Brás.

Para além do cantochão, neste antifonário foram identificados por Manuel Pedro Ferreira dois hinos a duas vozes para a festa de S. Bernardo da primeira metade do século XIII, que constituem até ao momento a referência mais antiga a um texto musical polifónico de origem portuguesa ${ }^{17}$. Trata-se de um bifólio que foi incorporado a quando da reencadernação de 1483, constituindo os fólios 2 e 3 do antifonário. Este contém vários hinos, nos quais se incluem dois dedicados a S. Bernardo: Exultat celi curia e Bernardus doctor inclitus. Para o primeiro destes hinos não foi encontrada qualquer concordância com outras fontes cistercienses ${ }^{18}$, sendo único no Ms 25. Para o segundo foi encontrada concordância apenas para o texto, mas com melodia diferente (até mesmo de outras fontes portuguesas da época), sendo única do Ms $25^{19}$.

A filiação deste e outros manuscritos pertencentes ao mosteiro de Arouca tem sido amplamente discutida. A hipótese de que o livro teria sido copiado no scriptorium do mosteiro espanhol de Las Huelgas por monges de Cîteaux tem sido posta de lado, uma vez que não terão residido monges dessa abadia francesa no mosteiro espanhol, tendo sido os livros de Las Huelgas importados e não realizados no mosteiro. A hipótese de que

\footnotetext{
${ }^{14}$ Este manuscrito encontra-se disponível em Portuguese Early Music Database, http://www.pemdatabase.eu.

${ }^{15}$ FERREIRA, Manuel Pedro, «Early Cistercian Polyphony: A Newly-Discovered Source», in Lusitania Sacra, 2. ${ }^{\text {a }}$ série, 13-14, 2001-2002, p.269.

${ }^{16}$ GOMES, Saul António, «A Congragação Cisterciense de Santa Maria de Alcobaça entre os séculos XVI e XVII: Elementos para o seu conhecimento», in Lusitania Sacra, 2. ${ }^{a}$ série, 18, 2006, pp. 386-387.

${ }^{17}$ FERREIRA, «Early Cistercian Polyphony: A Newly-Discovered Source», p. 269.

${ }^{18}$ Ibidem., p. 272.

${ }^{19}$ Ibidem., p. 274.
} 
terá sido copiado no scriptorium de Alcobaça parece consensual, uma vez que a relação do Ms 25 com os manuscritos produzidos nesta abadia não só tem concordância quanto à decoração (desenho das iniciais, cores e motivos utilizados), mas também relativamente a características notacionais que seguem a tradição de Clairvaux, abadia relacionada com Alcobaça $^{20}$.

Através de um estudo comparativo do ofício de Matinas para a festa de S. Bernardo presente no Ms 25, com o de outras fontes, pode-se perceber a sua filiação litúrgica e também algumas decisões tomadas pelo scriptorium na sua realização. Neste estudo o Ms 25 foi comparado com outras quatro fontes, na sua maioria provenientes do Norte de França e Europa Central, relativamente às rubricas constantes no ofício de Matinas ${ }^{21}$. A primeira destas fontes é o manuscrito $1799^{* *}$, um antifonário actualmente conservado na Österreichische Nationalbibliothek - Handschriftensammlung, em Viena (A-Wn 1799**). Trata-se de um manuscrito copiado no século XIII (muito possivelmente pela mesma altura que o Ms 25), contendo ambos os ciclos do Temporale e Sanctorale, proveniente de Stift Rein, Steiermark (Áustria). O manuscrito 70 E 4, conserva-se actualmente na Koninklijke Bibliotheek, em Haia (NL-DHk 70 E 4). Trata-se de um compêndio litúrgico contendo ofícios para as festas da Virgem Maria, celebradas em Tongres (Limbourg, Bélgica), incluindo também outros ofícios desde o século XII a XIV. O ofício de Matinas para a festa de S. Bernardo aparece neste manuscrito entre os fólios 107v e 109v. Para o ofício, para além do invitatório, apenas são indicadas três antífonas e três responsórios para cada nocturno, sem a antífona ad Cantica para o terceiro nocturno, pelo que se conclui tratar-se de um manuscrito realizado segundo o cursus secular. Segue também o cursus secular o manuscrito 287 (olim XXIX), actualmente conservado na Stifsbibliothek, em Vorau, Áustria (A-VOR 287). Trata-se de um antifonário da primeira metade do século XIV contendo os ciclos do Temporale (divido entre Inverno e Verão) e do Sanctorale proveniente de Vorau, com adições posteriores para Salzburgo. De notar a existência no manuscrito de algumas festas pouco comuns assim como alguns erros textuais como a inserção, omissão, ou palavras erradas que foram corrigidas, aparecendo nas margens ou entre o texto original.

Em todos estes manuscritos, à excepção do manuscrito A-Wda D-4 (onde é indicado com o ofício para o comum de um confessor), a festa de S. Bernardo aparece especificamente indicada com os ofícios para as várias Horas Canónicas. No caso do A-Wda D-4 apenas têm concordância com o Ms 25 quatro antífonas e um responsório.

${ }^{20}$ Ibidem., p. 269. Nota 8

${ }^{21}$ A descrição do conteúdo de cada uma destas fontes está disponível em Cantus: A Database for Latin Ecclesiastical Chant, http://www.cantusdatabase.org. 
O Ofício de Matinas é consideravelmente mais extenso que os destinados às restantes Horas, incorporando, para além do invitatório (I), uma série de antífonas (A), versículos (W) e responsórios (R). Este ofício divide-se em três grandes secções, correspondendo cada uma a um nocturno. Segundo o cursus monástico, cada um dos três nocturnos é composto por uma série de leituras, intercaladas primeiramente por várias antífonas, seguidas por quatro responsórios, perfazendo assim um total de doze responsórios, contrariamente ao cursus secular com apenas nove responsórios. O número de antífonas no início de cada nocturno é variável consoante a importância da festa. Desta forma, o ofício de Matinas seria consideravelmente mais extenso que os das restantes Horas, sendo a sua extensão aumentada tratando-se de Matinas solenas, com a incorporação de mais seis antífonas com os respectivos salmos e lições.

A festa de S. Bernardo requeria, como mencionado acima, a comemoração com um ofício de doze lições (Matinas solenes). Este ofício aparece no Ms 25 com o invitatório correspondente seguido pelo primeiro nocturno, composto por seis antífonas, um versículo e os responsórios I a IV com os respectivos versos, terminando o quarto com a doxologia Gloria Patri... a seguir ao verso do responsório IV. O mesmo sucede no segundo nocturno, também composto por seis antífonas, terminando com um versículo, e um grupo de quatro responsórios (V a VIII), com a doxologia Gloria Patri... a seguir ao verso do responsório VIII. No início do terceiro nocturno apenas é indicada a antífona ad Cantica e cântico associado (geralmente retirado do Antigo Testamento) seguida de um versículo. Após estas rubricas, aparecem os quatro últimos responsórios (IX a XII), terminando o último com a doxologia Gloria Patri... a seguir ao verso do responsório XII.

O invitatório In confessione laudis, com que inicia o ofício de Matinas, encontra-se no Modo IV. No final do segundo tetragrama encontra-se indicado o incipit do salmo 94 Venite exultemus Domino, que costuma acompanhar o invitatório.

\begin{tabular}{|c|c|c|c|c|c|}
\hline Fólio & Gén. & Incipit & M & CANTUS & Concordâncias \\
\hline $093 \mathrm{r}$ & I & In confessione laudis adoremus & 4 & 100139 & $\begin{array}{l}\text { A-Wn 1799**; NL-DHk } 70 \\
\text { E } 4\end{array}$ \\
\hline
\end{tabular}

Trata-se de uma melodia relativamente elaborada com a predominância de neumas de duas notas (pes e clivis), de três notas (porrectus, climacus e torculus) e de neumas compostos (subpunctis). O texto possui concordância com os antifonários A-Wn 1799** e NL-DHk 70 E 4, omitindo estas duas últimas fontes o nome do Santo. 
O primeiro nocturno abre com um grupo de seis antífonas (com um versículo após a sexta) seguidas de quatro responsórios.

\begin{tabular}{|c|c|c|c|c|c|}
\hline Fólio & Gén. & Incipit & $\mathbf{M}$ & CANTUS & Concordâncias \\
\hline \multicolumn{6}{|c|}{ Primeiro nocturno } \\
\hline $093 \mathrm{r}$ & $\mathrm{A}(1)$ & Viae viri sancti viae pulchrae & 1 & 205167 & $\begin{array}{l}\text { A-Wn } 1799 * * ; \text { NL-DHk } 70 \text { E 4; } \\
\text { A-VOR } 287\end{array}$ \\
\hline $093 \mathrm{r}$ & $\mathrm{A}(2)$ & Semitas justitiae viasque & 2 & 204587 & $\begin{array}{l}\text { A-Wn } 1799 * * ; \text { NL-DHk } 70 \text { E 4; } \\
\text { A-VOR } 287\end{array}$ \\
\hline $093 v^{0}$ & A (3) & Benedictio Domini super caput & 3 & 200650 & $\begin{array}{l}\text { A-Wn } 1799 * * ; \text { NL-DHk } 70 \text { E 4; } \\
\text { A-VOR } 287\end{array}$ \\
\hline $093 v^{0}$ & A (4) & Consurgens diloculo quaesivit & 4 & 200892 & $\begin{array}{l}\text { A-Wn } 1799^{* *} ; \text { NL-DHk } 70 \text { E 4; } \\
\text { A-VOR } 287\end{array}$ \\
\hline $093 v^{\circ}$ & $\mathrm{A}(5)$ & In testamentis pacis & 5 & 202491 & $\begin{array}{l}\text { A-Wn } 1799 * * ; \text { NL-DHk } 70 \text { E 4; } \\
\text { A-VOR } 287\end{array}$ \\
\hline $093 v^{0}$ & A (6) & Exaltavit Dominus in aeternum & 6 & 201693 & $\begin{array}{l}\text { A-Wn } 1799^{* *} ; \text { NL-DHk } 70 \text { E 4; } \\
\text { A-VOR } 287\end{array}$ \\
\hline $093 v^{0}$ & $\mathrm{~W}$ & Justum deduxit Dominus & $\mathrm{r}$ & 008115 & A-Wn $1799 * *$ \\
\hline $093 v^{0}$ & $\mathrm{R}(1)$ & Prima virtus viri sancti & 1 & 601881 & A-Wn $1799^{* *} ;$ NL-DHk 70 E 4 \\
\hline $094 \mathrm{r}$ & $\mathrm{V}$ & Totum in eo disciplinatum & 1 & 601881 & A-Wn 1799**; NL-DHk 70 E 4 \\
\hline $094 \mathrm{r}$ & $\mathrm{R}(2)$ & Virtute multa et scientia & 6 & 602516 & A-Wn 1799**; NL-DHk 70 E 4 \\
\hline $094 \mathrm{r}$ & $\mathrm{V}$ & A pueritia requisivit & 6 & $602516 a$ & A-Wn 1799**; NL-DHk 70 E 4 \\
\hline $094 \mathrm{r}$ & $\mathrm{R}(3)$ & Opera sancti patris velut sol & 2 & 601694 & A-Wn 1799**; NL-DHk 70 E 4 \\
\hline $094 \mathrm{r}$ & $\mathrm{V}$ & Non sunt abscondita $a b$ eo & 2 & $601694 a$ & A-Wn 1799**; NL-DHk 70 E 4 \\
\hline $094 v^{0}$ & $\mathrm{R}(4)$ & In timore Dei patris sancti & 1 & 601166 & A-Wn 1799**; NL-DHk 70 E 4 \\
\hline $094 v^{0}$ & $\mathrm{~V}$ & Pastor populi Dei & 1 & $601166^{\mathrm{a}}$ & A-Wn 1799**; NL-DHk 70 E 4 \\
\hline $094 v^{0}$ & $\mathrm{~V}$ & Gloria Patri, et Filio & 1 & & \\
\hline
\end{tabular}

A primeira antífona, Vie viri sancti, aparece indicada na mesma posição no Ms 1799**, 287 e 70 E 4, destinando-se também nos manuscritos ao ofício de Vésperas. No manuscrito 287 aparece indicada no ofício comum para um Confessor. A segunda antífona Semitas justitiae, tal como a anterior, também tem correspondência nos Ms 1799**, 287 e 70 E 4. As quatro antífonas seguintes, tal como as anteriores, também possuem concordância com os Ms 1799**, 287 e 70 E 4. As seis antífonas correspondem aos modos I a VI, com a primeira antífona no modo I, segunda no modo II e assim sucessivamente.

O versículo breve Justum deduxit Dominus é exemplo de uma das particularidades presentes nos manuscritos musicais provenientes do scriptorium de Alcobaça, que se prende com o uso da virga e do punctum. No caso dos manuscritos que seguem a tradição de Clairvaux, o uso da virga não é feito aleatoriamente. Esta é utilizada não só para indicar que a nota seguinte é mais aguda, mas também para indicar o início de cada 
palavra $^{22}$. Este versículo possui concordância no Ms 1799**, não possuindo concordância nos manuscritos 70 E 4 e Ms 287, uma vez que estes encontram-se organizados segundo o cursus secular.

O primeiro dos quatro responsórios para este nocturno, Prima virtus viri, possui concordância com os manuscritos $1799 * *$ e 70 E 4 . A letra inicial de "prima" é bastante mais ampla relativamente aos responsórios seguintes quanto ao tamanho e decoração. Esta é uma ocorrência comum no primeiro responsório para o ofício de Matinas, assim como na primeira antífona para o ofício de Laudes e nas antífonas ad Benedictus e ad Magnificat quando aparecem isoladas ${ }^{23}$. Estes quatro responsórios são melodicamente bastante elaborados, até mesmos os versos, que geralmente tendem a ser mais recitativos e silábicos, cada sílaba tem quase sempre associado um neuma de duas ou três notas. A seguir ao verso do quarto responsório aparece a doxologia Gloria Patri..., dada no Modo I, aquele em que está o responsório assim como o verso. O segundo nocturno, tal como o primeiro, é composto por seis antífonas, um versículo e quatro responsórios.

\begin{tabular}{|c|c|c|c|c|c|}
\hline Fólio & Gén. & Incipit & $\mathbf{M}$ & CANTUS & Concordâncias \\
\hline \multicolumn{6}{|c|}{ Segundo nocturno } \\
\hline $094 \mathrm{v}^{\mathrm{o}}$ & $\mathrm{A}(1)$ & Quasi oliva pullulans & 7 & 204077 & A-Wn 1799**; NL-DHk 70 E 4 \\
\hline $094 \mathrm{v}^{\circ}$ & $\mathrm{A}(2)$ & Porrexit manum suam & 8 & 203868 & A-Wn 1799**; NL-DHk 70 E 4 \\
\hline $094 v^{\circ}$ & A (3) & Ampliavit gentem suam & 1 & 200265 & A-Wn 1799**; NL-DHk 70 E 4 \\
\hline $095 \mathrm{r}$ & A (4) & Honoravit Deum & 2 & 202254 & $\begin{array}{l}\text { A-Wn 1799**; NL-DHk } 70 \text { E } 4 \\
\text { A-VOR 287; A-Wda D-4 }\end{array}$ \\
\hline $095 \mathrm{r}$ & A (5) & Extulit manus suas & 3 & 201770 & $\begin{array}{l}\text { A-Wn 1799**; NL-DHk } 70 \text { E } 4 \\
\text { A-VOR 287; A-Wda D-4 }\end{array}$ \\
\hline $095 \mathrm{r}$ & A (6) & Dedit Dominus sancto suo & 4 & 201138 & $\begin{array}{l}\text { A-Wn 1799**; NL-DHk } 70 \text { E } 4 \\
\text { A-VOR 287; A-Wda D-4 }\end{array}$ \\
\hline $095 \mathrm{r}$ & $\mathrm{W}$ & Amavit eum dominus & $\mathrm{r}$ & 00741 & A-Wn $1799 * *$ \\
\hline $095 \mathrm{r}$ & $\mathrm{R}(5)$ & O odoriferum lilium & 2 & 601686 & A-Wn 1799**; NL-DHk 70 E 4 \\
\hline $095 \mathrm{r}$ & $\mathrm{V}$ & Fac canentes & 2 & $601686^{\mathrm{a}}$ & A-Wn 1799**; NL-DHk 70 E 4 \\
\hline $095 \mathrm{r}$ & $\mathrm{R}(6)$ & Accepit vir Sanctus a Domino & 5 & 600021 & A-Wn 1799**; NL-DHk 70 E 4 \\
\hline $095 \mathrm{v}^{\circ}$ & $\mathrm{V}$ & Addidit ei gloriam & 5 & $600021^{\mathrm{a}}$ & A-Wn 1799**; NL-DHk 70 E 4 \\
\hline $095 v^{\circ}$ & $\mathrm{R}(7)$ & Lex veritatis in ore patris & 3 & 601327 & A-Wn 1799**; NL-DHk 70 E 4 \\
\hline $095 \mathrm{v}^{\circ}$ & $\mathrm{V}$ & In pace et aequitate & 3 & $601327^{\mathrm{a}}$ & A-Wn 1799**; NL-DHk 70 E 4 \\
\hline $095 v^{\circ}$ & $\mathrm{R}(8)$ & Testamentum aeternum & 1 & 602317 & A-Wn 1799**; NL-DHk 70 E 4 \\
\hline $095 \mathrm{v}^{\circ}$ & $\mathrm{V}$ & Magnalia honoris Dei??? & 1 & $602317^{\mathrm{a}}$ & A-Wn 1799**; NL-DHk 70 E 4 \\
\hline $095 \mathrm{v}^{\circ}$ & $\mathrm{V}$ & Gloria Patri, et Filio & 1 & & \\
\hline
\end{tabular}

${ }^{22}$ FORTU, Mara, «The Medieval Musical Manuscripts of the Cistercian Order in Portugal», in Barbara HAGGH e Debra LACOSTE (eds.), Cantus Planus: Papers read at the 15th meeting of the IMS study group, The Institute of Mediaeval Music, Lions Bay, 2013, p. 237.

${ }^{23}$ HUGHES, Andrew, Medieval Manuscripts for Mass and Office: A Guide to their Organization and p. 161. 
As seis antífonas do segundo nocturno possuem concordância com os manuscritos $1799^{* *}$ e 70 E 4. Possuem também concordância com os manuscritos 287 e D-4 as antífonas Honoravit Deum, Extulit manus e Dedit Dominus. Tal como o versículo do primeiro nocturno, também o versículo a seguir às seis antífonas no segundo nocturno possui as mesmas características notacionais que o versículo destinado ao primeiro nocturno. Este versículo possui apenas concordância com o manuscrito $1799 * *$.

Os quatro responsórios destinados a este nocturno são, tal como os do nocturno anterior, bastante elaborados melodicamente, com praticamente nenhuma divisão silábica, predominando (embora breves) melismas para cada sílaba. O mesmo acontece nos versos, também elaborados melodicamente fugindo a um estilo mais recitativo. A doxologia Gloria Patri... aparece a seguir ao verso do quarto responsório, estando no modo I, de acordo com o modo do responsório.

Para o terceiro nocturno está indicada uma antífona, um versículo e os quatro responsórios, perfazendo o total de doze.

\begin{tabular}{|c|c|c|c|c|c|}
\hline Fól. & Gén. & Incipit & $\mathbf{M}$ & CANTUS & Concordâncias \\
\hline \multicolumn{6}{|c|}{ Terceiro nocturno } \\
\hline 096r & A & Replevit Sanctum suum & 7 & 204261 & $\begin{array}{l}\text { A-Wn } 1799 * * ; \text { NL-DHk } 70 \text { E 4; } \\
\text { A-VOR 287; A-Wda D-4 }\end{array}$ \\
\hline $096 \mathrm{r}$ & $\mathrm{W}$ & Justus ut palma & $\mathrm{r}$ & 008117 & A-Wn 1799** \\
\hline 096r & $\mathrm{R}(9)$ & O oliva fructifera in domo & 7 & 601612 & A-Wn 1799**; NL-DHk 70 E 4 \\
\hline 096r & $\mathrm{V}$ & Introisti in potentias & 7 & 601612a & A-Wn 1799**; NL-DHk 70 E 4 \\
\hline 096r & $\bar{R}(10)$ & Beatus Bernardus quasi vas & 8 & 600239 & $\begin{array}{l}\text { A-Wn 1799**; NL-DHk } 70 \text { E 4; } \\
\text { A-VOR 287; A-Wda D-4 }\end{array}$ \\
\hline $096 \mathrm{v}^{\circ}$ & $\mathrm{V}$ & Factus est quasi ignis & 8 & $600239 a$ & $\begin{array}{l}\text { A-Wn } 1799 * * ; \text { NL-DHk } 70 \text { E } 4 ; \\
\text { A-VOR 287; A-Wda D-4 }\end{array}$ \\
\hline $096 v^{\circ}$ & $\mathrm{R}(11)$ & Habebat pater venerabilis & 1 & 600991 & A-Wn 1799**; NL-DHk 70 E 4 \\
\hline $096 \mathrm{v}^{\circ}$ & $\mathrm{V}$ & In vultu potentium & 1 & 600991a & A-Wn 1799**; NL-DHk 70 E 4 \\
\hline $096 \mathrm{v}^{\circ}$ & $\mathrm{R}(12)$ & Dedit Dominus & 1 & 600542 & A-Wn 1799**; NL-DHk 70 E 4 \\
\hline $096 \mathrm{v}^{\circ}$ & $\mathrm{V}$ & Dedit decus & 1 & 600542a & A-Wn 1799**; NL-DHk 70 E 4 \\
\hline $097 \mathrm{r}$ & V & Gloria Patri, et Filio & 1 & & \\
\hline
\end{tabular}

A antífona ad cantica, com que inicia o terceiro nocturno, é específica do cursus monástico. Esta antífona, como a indicação sugere, deveria ser cantada com três cânticos, retirados do Antigo Testamento (fora do saltério) antes dos responsórios. Esta antífona apenas possui concordância para esta função nos manuscritos $1799^{* *}$ e $70 \mathrm{E} 4$, tendo também concordância nos dois manuscritos do cursus secular, constituindo-se como a primeira das três antífonas destinadas ao terceiro nocturno. 
O versículo Justus ut palma aparece, tal como os dois anteriores, apenas no manuscrito 1799**. Uma vez que se trata de uma rubrica comum a outras festas (tendo já aparecido em festas precedentes) apenas é dado o incipit. Os responsórios do terceiro nocturno apresentam-se também elaborados melodicamente assim como os respectivos versos. Como nos nocturnos anteriores a doxologia Gloria Patri... surge após o verso do último responsório no modo I.

O ofício de Matinas para a festa de S. Bernardo incorporado nas fontes de uso cisterciense possui um carácter solene, com uma extensão maior relativamente a outras festividades do ano litúrgico. Não sendo um exemplo único na liturgia cisterciense, uma vez que outras festas como a de S. Bento, Purificação da Virgem, S. João Baptista também possuem Matinas solenes, a música para a festa de S. Bernardo reveste-se de um carácter particular, pela atenção dada à construção melódica das rubricas do seu Ofício. Identificam-se como características gerais a colocação do texto e música de forma mais rigorosa relativamente a outras partes do manuscrito, com a inclusão de alguma ornamentação nas letras iniciais de cada rubrica. As rubricas são mais extensas que as de outras festas, com um forte desenho melismático, privilegiando a extensão de determinadas palavras, sendo o nome do Santo uma das principais. A construção elaborada das rubricas para o ofício de Matinas (solenes) da festa de S. Bernardo constitui-se assim, não só como um exemplo da importância litúrgico-musical que este Santo tem na comunidade de S. Pedro e S. Paulo de Arouca no início do século XIII, mas também em outras comunidades europeias, que partilham das mesmas características musicais presentes no manuscrito 25 do Museu de Arte Sacra de Arouca. 